\title{
AVALIAÇÃO DA GERAÇÃO DE RESÍDUOS DE CONSTRUÇÃO CIVIL (RCC) NO PROCESSO DE ASSENTAMENTO CERÂMICO
}

\author{
L. P. GUIMARÃES ${ }^{1}$, M. GIANEZINI ${ }^{2}$, V. M. BRISTOT ${ }^{3}$, Y. B. EMERIM ${ }^{4}$ e M. L. F. GUIMARÃES 5 \\ Universidade do Extremo Sul Catarinense \\ Ipg@unesc.net ${ }^{1}$
}

Artigo submetido em 18/12/2017 e aceito em 04/11/2019

DOI: 10.15628/holos.2019.6694

\section{RESUMO}

A construção civil é um setor importante na economia, principalmente em tempos de crise financeira e elevadas taxas de desemprego, devido à baixa qualificação exigida da mão-de-obra. Os resíduos da construção civil (RCC's) são responsáveis por grande parcela dos resíduos sólidos urbanos, fator ligado a qualidade da mão-de-obra. Deste modo, este artigo objetivou quantificar a geração de resíduos provenientes do processo de assentamento cerâmico em construções de edifícios. Os resultados foram obtidos em construções no município de Criciúma/SC, onde, foram estudadas duas construtoras. A partir dos resultados, foi possível estimar a geração de resíduos na cidade em questão. Bem como, realizar uma comparação afim de evidenciar a variação na geração de resíduos entre duas construtoras diferentes da mesma cidade. Além disso, através de classificação fornecida pelos mestres de obras responsáveis, obteve-se uma escala de qualificação da mão-de-obra, afim de comparar a geração de resíduos entre diferentes qualificações. Outro indicador estudado, é em relação ao PBQP-H, onde, compara-se a média de resíduos gerados, em uma construtora certificada e outra que não possui a certificação.

PALAVRAS-CHAVE: Construção civil, resíduos de construção civil, PBQP-H.

\section{EVALUATION OF THE GENERATION OF WASTE FROM BUILDING IN CERAMIC SEALING PROCESS}

\begin{abstract}
Civil construction is an important sector of the economy, especially in times of financial crisis and high unemployment, due to the low qualification required of the labor. Waste from construction (RCC's) accounts for a large share of municipal solid waste, a factor linked to the quality of the workforce. Thus, this article aimed to quantify the generation of residues from the ceramic laying process in buildings. The results were obtained in constructions in the city of Criciúma-SC, where two constructors were studied. From the results, it was possible to estimate the generation of waste in the city in
\end{abstract}

question. As well, make a comparison to show the variation in generation of waste between two different builders of the same city. In addition, through a classification provided by the responsible works masters, a qualification scale of the workforce was obtained, to compare the generation of waste between different qualifications. Another indicator studied is in relation to the PBQP-H, where the average of waste generated is compared in a certified construction company and other one that does not have the certification.

KEYWORDS: Construction, waste from construction, PBQP-H. 


\section{INTRODUÇÃO}

A baixa capacitação profissional exigida para os trabalhadores da indústria da construção civil torna-se um importante elemento quando há um cenário econômico desfavorável com elevadas taxas de desemprego, onde os empregadores conseguem "captar" mão-de-obra mais facilmente e com baixo custo.

A Indústria da Construção Civil é responsável por aproximadamente $70 \%$ da formação de capital da economia do Brasil, segundo Mello (1997). Esse ambiente acaba causando uma concorrência natural de mercado, o lucro é visado como principal prioridade. Este fator gera, devido ao baixo custo, uma mão de obra não qualificada, sem padrão de qualidade, desta forma os desperdícios durante os processos na construção civil tornam-se significativos, gerando grande impacto ambiental.

Segundo dados fornecidos pela Divisão de Planejamento Físico e Territorial da prefeitura de Criciúma, entre os meses de dezembro de 2015 e fevereiro de 2016, foram emitidos 14 alvarás para construção de edifícios, da Indústria da Construção Civil Subsetor Edificações (ICCSE), totalizando $64.433 \mathrm{~m}^{2}$ de área a ser construída. Utilizando dados de Novaes e Mourão (2008), para esse total de área a ser construída, estima-se que seja gerado até 20.000ton de resíduos de construção civil (RCC), na cidade de Criciúma, considerando que todas essas obras sejam finalizadas, e mantenham suas áreas.

Dados como este, serviram de incentivo para um estudo quantitativo, a fim de analisar o volume de resíduo gerado em uma etapa da construção civil, para que assim seja possível, futuramente, auxiliar na busca de alternativas que visem a diminuição dos impactos ambientais causados pela construção civil.

Este trabalho tem como objetivo identificar e quantificar os resíduos gerados durante o processo de assentamento cerâmico, bem como verificar a existência ou não de uma relação da geração de resíduos entre construtoras que possuem a certificação pelo Programa da Qualidade e Produtividade no Habitat (PBQP-H) e empresas que não possuem.

\section{REFERENCIAL TEÓRICO}

Nesta seção, optou-se por uma revisão com referencial bibliográfico técnico-científico e documental, a fim de apresentar os aspectos relacionados a construção civil, mais especificamente assentamento de cerâmica, e o para entender o que o PBQP-H tem feito em relação ao gerenciamento dos processos da ICCSE.

\subsection{Construção Civil}

Cavassin (2011) explica, utilizando vários exemplos na história, que a evolução da construção civil tem grande impacto no estabelecimento de uma população, bem como, é de grande importância para a cultura.

Segundo Toledo, Abreu e Jungles (2000), existem algumas particularidades no setor de construção civil, como: vida útil longa dos produtos; dependência entre empresas; dependência 
de outros setores industriais; além da natureza das inovações na construção predominantemente gradual, com uma baixa frequência de inovações radicais.

De acordo com Rezende e Abiko (2004), a construção civil é constituída apenas de pequenos empreendimentos com fracos ou nenhum departamento de pesquisa, tornando a inovação provinda apenas de fornecedores. Isto faz do setor, ser caracterizado como conservador.

A Associação Brasileira para Reciclagem de Resíduos da Construção Civil (ABRECON) 2017, diz que o segmento da reciclagem de resíduos da construção e demolição no Brasil ainda é rudimentar. A reciclagem deste tipo de resíduo é um mercado desenvolvido em muitos países da Europa, em grande parte devido à escassez de recursos naturais que aqueles países possuem.

Os resíduos de construção civil (RCC) acumulados, quando descartados indiscriminadamente em corpos de água, elevam o seu leito, causando o assoreamento, resultando enchentes e riscos de desabamento de residências próximas aos rios (ABRECON, 2017).

\subsubsection{Assentamento Cerâmico}

Paulon (1991) explica que após a Segunda Guerra Mundial, com a possibilidade de produção em escala industrial, os preços dos revestimentos cerâmicos baixaram de preço, tornando-os mais acessíveis para a população em geral. Desta forma, cada vez mais, este, se tornou um tema recorrente de estudos e desenvolvimento.

Segundo Junginger (2003), existem três camadas base de revestimentos cerâmicos, a camada de regularização, camada de fixação e camada de acabamento. A Figura 1, expõe as camadas utilizadas em assentamentos cerâmicos.

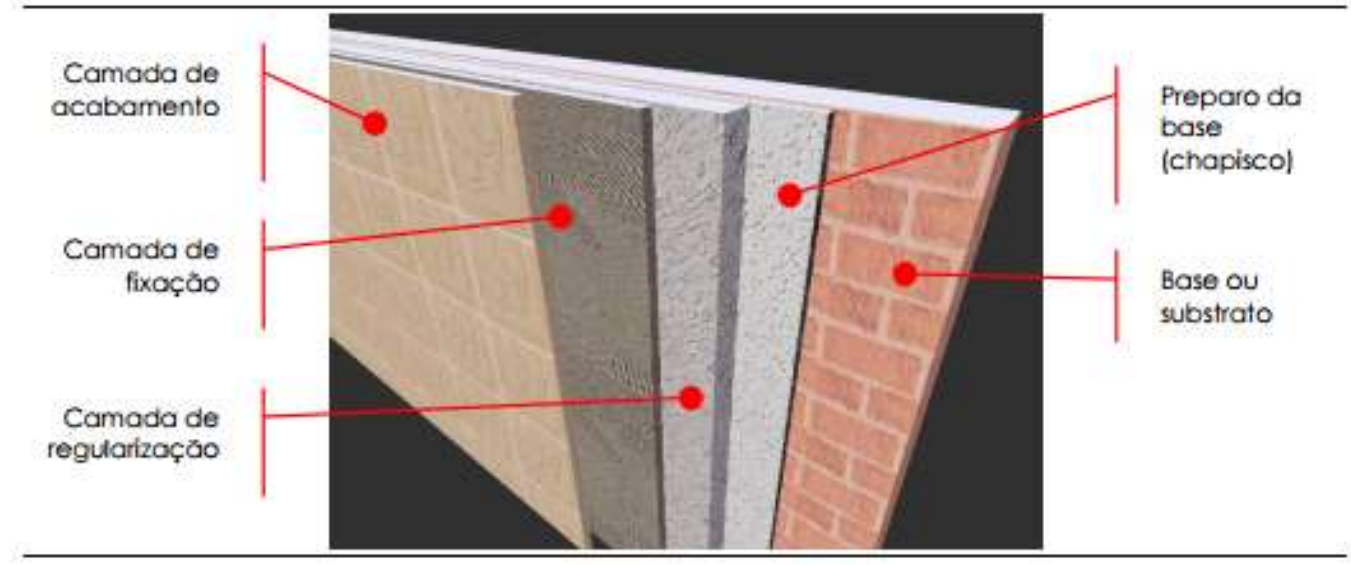

Figura 1: Camadas base de assentamentos cerâmicos. Junginger (2003)

- Camada de Regularização: Em locais onde essa camada é utilizada, tem-se por principal objetivo tornar a superfície adequada para receber as placas cerâmicas. Desta forma, esta camada deve possuir resistência mecânica, planeza, capacidade para absorver deformações, homogeneidade e regularidade de superfície (Junginger, 2003).

- Camada de Fixação: É responsável pena união das placas cerâmicas ao substrato. Comumente, utiliza-se argamassas de cimento e areia dosadas a argamassas adesivas, desta forma promovem aderência mecânica e química. (Junginger, 2003). 
A argamassa adesiva é composta de areia, cimento e aditivos que possuem composição variável dentre cada laboratório (BRITSCH, 1986).

- Camada de Acabamento: Composta das placas cerâmicas e rejuntes (Junginger, 2003). Tem por finalidade proteção, isolamento térmico e acústico, segurança ao fogo, aspecto estético, facilidade de limpeza e higiene, durabilidade do material. (Silva, 2015). Composta de argila e outros elementos inorgânicos (SINDUSCON, 2009).

\subsection{PROGRAMA BRASILEIRO DA QULIDADE E PRODUTIVIDADE NO HABITAT (PBQP-H)}

De acordo com o Ministério das Cidades (2017), o PBQP-H, é uma ferramenta do Governo Federal para o cumprimento da Carta de Istambul (Conferencia do Habitat II de 1996). Tem como objetivo organizar o setor da construção civil melhorando a qualidade do habitat e gerando modernização produtiva. Segundo Januzzi (2010), o programa é baseado na norma ISO 9000 e sofre atualizações periódicas, para que possa manter-se próxima a ISO.

Em 1998, com nome de Programa Brasileiro da Qualidade e Produtividade na Construção Habitacional, foi criado o primeiro escopo deste instrumento, em 2000 houve a necessidade de ampliar o programa, integrando assim outras áreas. Desta forma, $\mathrm{o} \mathrm{H}$, antes nomeado pela palavra "Habitação", passou a ser "Habitat", conceito mais amplo, que passou a envolver também saneamento e estrutura urbana (BRASIL, 2017).

O PBQP-H, envolve as etapas da cadeia produtiva configurada nos seus programas desenvolvidos aumentando a competitividade do setor, incluindo a modernização técnica e gerencial das empresas. Desta forma, gera ganhos para a cadeia produtiva, provocando benefícios como: aumento da qualidade nos produtos; ganhos em produtividade pela melhoria nos processos de produção de materiais de construção e na execução de obras; moradia de melhor qualidade; redução dos custos por meio da redução dos desperdícios de material e melhoria na qualificação das construtoras; modernização tecnológica e gerencial por intermédio do fortalecimento da infraestrutura laboratorial e de pesquisa para desenvolvimento tecnológico; qualificação de recursos humanos e satisfação do cliente (Florim e Quelhas, 2004).

Para sua a realização, se faz necessário promover o desenvolvimento e implantação de mecanismos de garantia da qualidade para os projetos e obras, garantir a qualidade dos materiais e componentes, opor-se as não conformidades de materiais, componentes e sistemas construtivos, criar programas para a qualificação da mão-de-obra em todos os níveis, ampliar o estoque de moradias e melhorar as já existentes, coletar e disponibilizar as informações do programa, apoiar e incentivar inovações tecnológicas e por fim promover a melhoria da qualidade de gestão nas diversas formas de projetos e obras habitacionais (BRASIL, 2017). Atualmente, cerca de 3000 empresas estão ativas entre as fases de implantação do programa. Para participar é necessário ser uma empresa construtora, responsável pela construção, reforma, fabricação, recuperação ou ampliação de uma obra (BRASIL, 2017).

No encerramento desta seção, cabe mencionar a amplitude do Programa Brasileiro da Qualidade e Produtividade na Construção Habitacional que perpassa seus objetivos, pois responde tanto aos deveres constitucionais da União, servindo de subsídio para elaborar e executar planos 
de desenvolvimento econômico e social, quanto contribuindo para instituir diretrizes para a habitação e o desenvolvimento urbano.

\section{METODOLOGIA}

O trabalho transcorreu em um primeiro momento, por meio de pesquisas bibliográficas e buscas em repositórios de universidades, centralizando a procura em artigos, teses, e dissertações, com o tema relacionado a resíduos da construção civil. O objetivo específico da pesquisa bibliográfica, incidiu na busca por fontes de dados, com informações relevantes sobre a quantidade e a composição dos RCC's gerados no Brasil, com intuito de fomentar o conhecimento científico sobre o tema a ser estudado.

Em um segundo momento, já com embasamento teórico, foram realizadas visitas em canteiros de obras em duas das maiores construtoras da cidade de Criciúma, uma que possui a certificação PBQP-H, e a outra sem certificação. Iniciou-se então, a coleta de dados, onde durante as visitas, eram realizadas as pesagens dos materiais descartados, os resíduos derivados da construção.

A coleta de dados aconteceu em edifícios que pertencem a ICSSE, e durante o processo de assentamento cerâmico. Após a execução de determinada área, os subempreiteiros acumulavam o resíduo gerado em um espaço, e em data previamente acertada com o pesquisador, era realizada a visita aos canteiros de obra com objetivo de pesar os resíduos gerados. Os resíduos eram postos em baldes de vinte litros, e com o auxílio de uma balança portátil digital de gancho, obtinha-se o peso do resíduo gerado e registrava-se em uma planilha impressa, conforme modelo disponível em ANEXO I, após isso, os resíduos seguiam para o descarte, conforme o modus operandi da empresa.

Foram levantadas também, informações que se julgou relevantes para a pesquisa, como a área construída, e a qualificação do profissional, de acordo com nota estabelecida pelo mestre de obras. O mestre de obras indicava uma nota de 1 a 5 para o subempreiteiro, utilizando os critérios: rapidez e qualidade do serviço realizado. Para as notas 1 e 2, a qualificação da mão-de-obra foi considerada ruim, para nota 3, regular, e para as notas 4 e 5, boa. 0 intuito da classificação da mão-de-obra, foi após o levantamento de dados, comparar entre os subempreiteiros, se os profissionais mais qualificados geravam menos resíduos.

Finalizadas as visitas, iniciou-se o trabalho estatístico, foram calculadas as quantidades de resíduo gerada de acordo com a área construída e a qualificação da mão-de-obra. Por fim, foram comparados os dados obtidos das duas construtoras, e observado se há ou não uma relação entre o PBQP-H e a quantidade de resíduo gerado.

O trabalho foi desenvolvido com base em pesquisa realizada com sete subempreiteiros, de duas diferentes construtoras da região. Por se tratar de um estudo comparativo, a fim de não gerar danos à suas imagens, as identidades das construtoras e dos subempreiteiros serão mantidas em sigilo durante todo o trabalho, sendo as construtoras diferenciadas por A e B, e os subempreiteiros por meio de números. 


\section{RESULTADOS E DISCUSSÃO}

Durante a coleta de dados, observou-se a composição dos resíduos gerados durante o processo de assentamento cerâmico, que é geralmente formado por: placas cerâmicas (pisos e azulejos), argamassa e poeira.

\subsection{Construtora A}

Durante as visitas a Construtora $A$, foram estudados e quantificados os resíduos gerados por 4 subempreiteiros. Atualmente, a empresa não possui certificação PBQP-H. A Tabela 1 apresenta os totais de área construída e quantidade em quilos de resíduo gerado dos 4 subempreiteiros analisados da empresa.

\begin{tabular}{c|c|c}
\multicolumn{3}{c|}{ Tabela 1: Totais de área construída e resíduo gerado - Construtora A } \\
\hline Item & $\begin{array}{c}\text { Área Construída } \\
\left(\mathrm{m}^{2}\right)\end{array}$ & $\begin{array}{c}\text { Resíduo Gerado } \\
(\mathrm{Kg})\end{array}$ \\
\hline Subempreiteiro 1 & 613,00 & 381,18 \\
Subempreiteiro 2 & 15,00 & 12,00 \\
Subempreiteiro 3 & 33,95 & 20,90 \\
Subempreiteiro 4 & 292,00 & 197,38 \\
Totais & 953,95 & 611,46 \\
\hline
\end{tabular}

A variação dos números de área construída e resíduo gerado entre os subempreiteiros, ocorreu devido ao número de visitas realizadas em cada obra, por vezes não era possível realizar a coleta com o mesmo colaborador, com um colaborador tendo somente uma visita por exemplo, ainda assim os dados foram mantidos na pesquisa, pois parte-se da ideia que quanto mais abrangente bem como mais dados forem utilizados para a estatística, melhor ela estará representando a realidade.

Dividindo o total de resíduo gerado de cada colaborador em quilogramas, pela área construída em $\mathrm{m}^{2}$, obteve-se a média de geração de resíduo por $\mathrm{m}^{2}$ de área construída. A Tabela 2 indica as médias obtidas, e a qualificação da mão-de-obra de acordo com o mestre de obras responsável.

Tabela 2: Média de resíduo gerado por área construída e classificação da mão-de-obra - Construtora A

\begin{tabular}{c|c|c}
\hline Item & $\begin{array}{c}\text { Resíduo gerado / } \\
\text { Área construída } \\
\left(\mathrm{Kg} / \mathrm{m}^{2}\right)\end{array}$ & $\begin{array}{c}\text { Classificação da } \\
\text { mão-de-obra }\end{array}$ \\
\hline Subempreiteiro 1 & 0,62 & 5,00 \\
Subempreiteiro 2 & 0,80 & 2,00 \\
Subempreiteiro 3 & 0,62 & 3,00 \\
Subempreiteiro 4 & 0,68 & 3,00 \\
Média Construtora A & 0,68 & 3,25 \\
Desvio Padrão & 0,08 & 1,26 \\
\hline
\end{tabular}

Constatou-se uma média aritmética da Construtora $A$ de $0,68 \pm 0,08 \mathrm{Kg} / \mathrm{m}^{2}$ de resíduo gerado durante o processo de assentamento cerâmico. O subempreiteiro com maior geração de resíduo foi o Subempreiteiro 2 , com $0,8 \mathrm{Kg} / \mathrm{m}^{2}$, isso pode ter ocorrido devido à uma menor 
amostragem em relação aos demais, mas vale ressaltar também, foi classificado como mão-deobra ruim (Nota 2, em escala de 1 a 5) pelo mestre de obras. Já o subempreiteiro com menor geração de resíduo, foi o Subempreiteiro 1 , com $0,62 \mathrm{~kg} / \mathrm{m}^{2}$, o Subempreiteiro 3 obteve também a mesma média, mas com uma amostragem inferior. A classificação da mão-de-obra foi realizada de acordo com o foi que julgado pelo mestre de obras, tendo como referência e parâmetros os outros subempreiteiros da empresa, sua média ficou em $3,25 \pm 1,26$, regular pela escala desenvolvida para o trabalho.

A Figura 2 ilustra uma comparação da média de geração de resíduo entre os colaboradores da Construtora A.

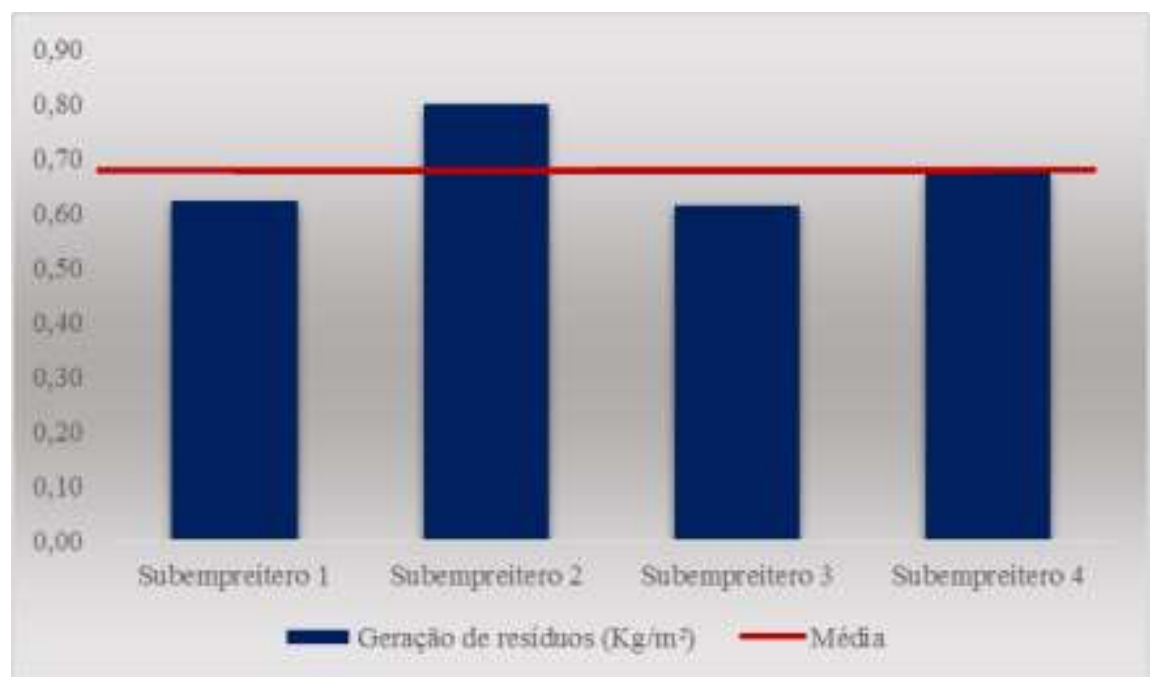

Figura 2: Comparação da geração de resíduos entre os Subempreiteiros da Construtora A

Nota-se um equilíbrio da geração de resíduo com diferentes subempreiteiros da empresa, comprovado por um desvio padrão de $0,086 \mathrm{Kg} / \mathrm{m}^{2}$, tomando como base a média, a maior variação encontrada foi do Subempreiteiro $2, \operatorname{com} 0,12 \mathrm{Kg} / \mathrm{m}^{2}$ de diferença.

Talvez esse fator se explique, devido a uma maior padronização dos processos na empresa, se todos os colaboradores trabalharem utilizando os mesmos métodos, em função de treinamentos, espera-se que os resultados sejam semelhantes, já quando utilizam métodos diferentes de trabalho, pode acabar ocasionando resultados distintos, ou ainda com maior imprecisão.

\subsection{Construtora B}

Durante as visitas a Construtora B, foram estudados e quantificados os resíduos gerados por 3 subempreiteiros. Atualmente, a empresa possui certificação $\mathrm{PBQP}-\mathrm{H}$, garantindo maior qualidade no serviço prestado. A Tabela 3 mostra os totais de área construída e quantidade em quilos de resíduo gerado dos 3 subempreiteiros analisados da empresa. 
Tabela 3: Totais de área construída e resíduo gerado - Construtora B

\begin{tabular}{c|c|c}
\hline Item & $\begin{array}{c}\text { Área Construída } \\
\left(\mathrm{m}^{2}\right)\end{array}$ & $\begin{array}{c}\text { Resíduo Gerado } \\
(\mathrm{Kg})\end{array}$ \\
\hline Subempreiteiro 1 & 87,50 & 106,38 \\
Subempreiteiro 2 & 325,55 & 567,69 \\
Subempreiteiro 3 & 221,50 & 393,15 \\
Total: & 634,55 & $1.067,22$ \\
\hline
\end{tabular}

Percebe-se que no caso da Construtora $B$, foi gerado mais de um quilo de resíduo por $\mathrm{m}^{2}$ de obra, já é um panorama diferente do que foi visto na construtora $A$.

Como já realizado na Construtora $A$, dividiu-se o total de resíduo gerado de cada colaborador em quilogramas, pela área construída em $\mathrm{m}^{2}$, e obteve-se a média de geração de resíduo por $\mathrm{m}^{2}$ de área construída. A Tabela 4 indica as médias obtidas, e a classificação da mãode-obra de acordo com o mestre de obras responsável.

Tabela 4: Média de resíduo gerado por área construída e classificação da mão-de-obra - Construtora B

\begin{tabular}{c|c|c}
\hline Item & $\begin{array}{c}\text { Resíduo gerado / } \\
\text { Área construída } \\
\left(\mathrm{Kg} / \mathrm{m}^{2}\right)\end{array}$ & $\begin{array}{c}\text { Classificação da } \\
\text { mão-de-obra }\end{array}$ \\
\hline Subempreiteiro 1 & 1,22 & 5,00 \\
Subempreiteiro 2 & 1,74 & 4,00 \\
Subempreiteiro 3 & 1,77 & 5,00 \\
Média Construtora B & 1,58 & 4,67 \\
Desvio Padrão & 0,31 & 0,58 \\
\hline
\end{tabular}

O subempreiteiro que registrou a maior média de geração de resíduos por $\mathrm{m}^{2}$ de obra foi o Subempreiteiro 3 , com $1,77 \mathrm{Kg} / \mathrm{m}^{2}$, já o responsável pela menor média constatada, foi o Subempreiteiro 1, com 1,22 Kg/m². A empresa registrou uma média aritmética de 1,58 Kg/m².

A média da classificação da mão-de-obra foi de 4,67 $\pm 0,58$, considerada boa de acordo com a escala definida para elaboração do trabalho. A Figura 3 ilustra uma comparação da média de geração de resíduo entre os colaboradores da Construtora B.

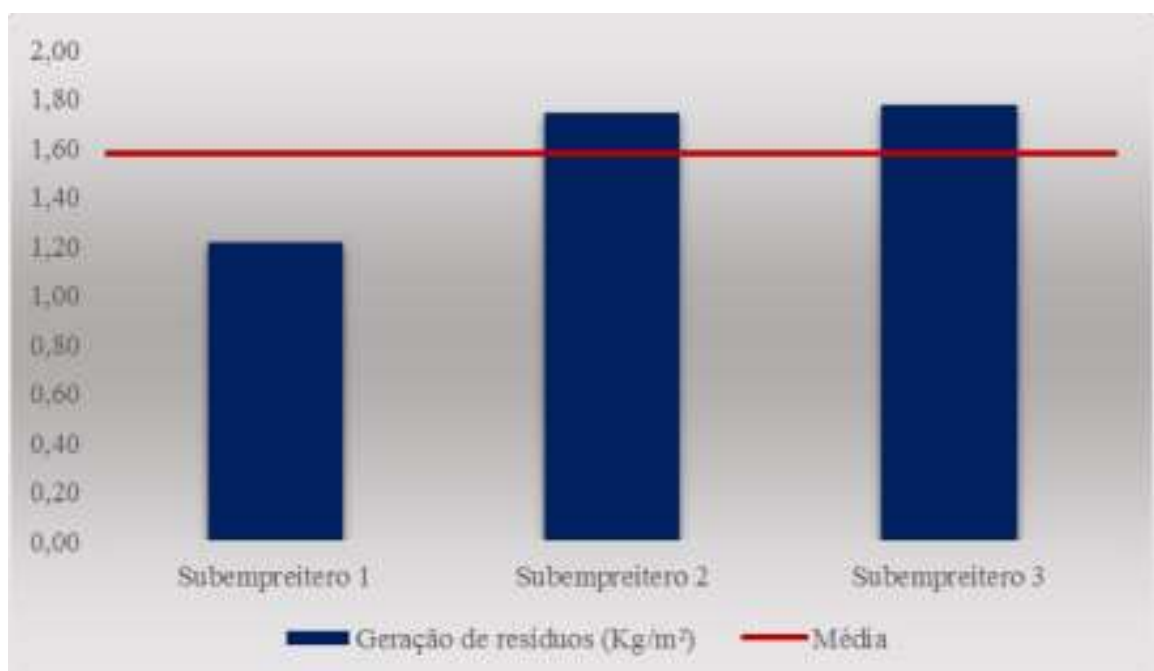

Figura 3: Comparação da geração de resíduos entre os Subempreiteiros da Construtora B 
A construtora B apresentou um desvio padrão de $0,31 \mathrm{~kg} / \mathrm{m}^{2}$, enquanto a maior variação da média, foi do subempreiteiro $1 \mathrm{com} 0,36 \mathrm{Kg} / \mathrm{m}^{2}$.

\subsection{Comparação entre as construtoras}

Os dados coletados durante a pesquisa, demonstram valores muito diferentes entre as duas empresas, com a Construtora $B$ apresentando valores muito superiores na geração de resíduos em relação à Construtora A. A Figura 4 ilustra a diferença da geração de resíduos por área construída entre as duas construtoras.

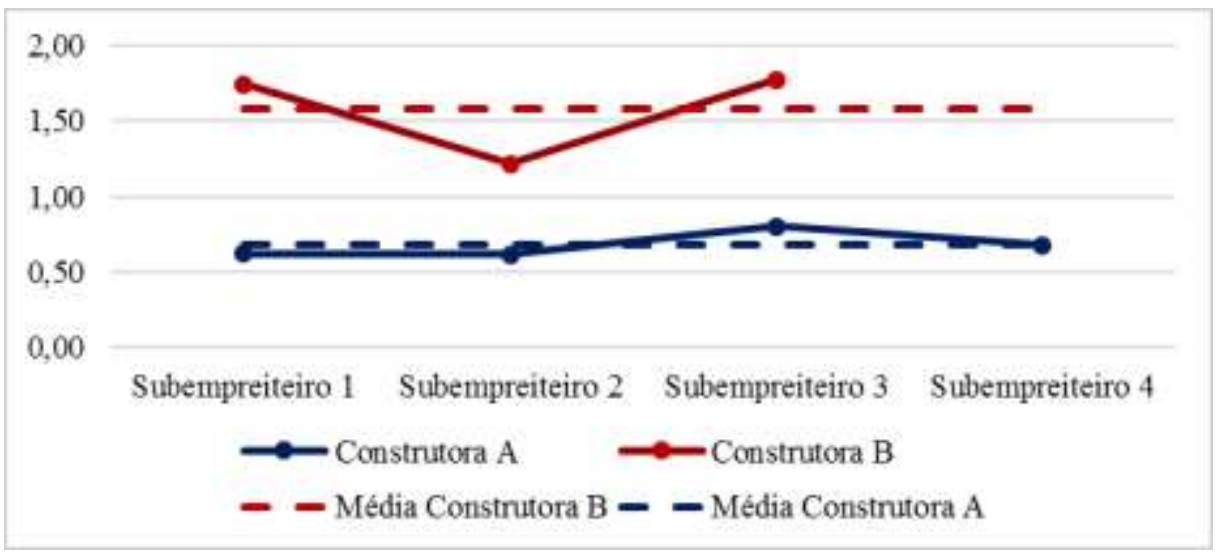

Figura 4: Comparação da geração média de resíduos por área construída entre as duas construtoras

Por meio da Figura 4, é possível visualizar a disparidade dos valores nas duas construtoras, com a Construtora $B$ apresentando uma geração de resíduo muito maior em relação à Construtora A. O subempreiteiro com menor geração de resíduos da Construtora $B$, gera aproximadamente $1,22 \mathrm{Kg} / \mathrm{m}^{2}$, já o subempreiteiro com menor geração de resíduos da Construtora $A$, gera aproximadamente $0,62 \mathrm{Kg} / \mathrm{m}^{2}$, comparando-os individualmente, os dois melhores desempenhos, em relação a geração de resíduo, apresentam uma diferença de quase o dobro de geração de resíduo. Mesmo que se compare o mesmo subempreiteiro da Construtora $\mathrm{B}$, com o subempreiteiro com maior geração de resíduos da Construtora $A$, ainda tem-se uma grande diferença, já que o maior gerador de resíduo da Construtora $A$, apresentou geração média de $0,80 \mathrm{Kg} / \mathrm{m}^{2}$.

Comparando as médias obtidas das duas empresas, tem-se a geração média de resíduo de $0,68 \mathrm{Kg} / \mathrm{m}^{2}$ para Construtora $\mathrm{A}$, e $1,58 \mathrm{Kg} / \mathrm{m}^{2}$, uma diferença de $0,90 \mathrm{Kg} / \mathrm{m}^{2}$, em outras palavras, baseando-se nos dados coletados dos sete subempreiteiros estudados, pode-se afirmar que a Construtora $B$, gera mais que o dobro de resíduo por $\mathrm{m}^{2}$ em relação a Construtora $A$ no processo de assentamento cerâmico.

\subsubsection{Relação com a classificação da mão-de-obra}

A Figura 5, apresenta a variação da geração de resíduos de acordo com a classificação da mão-de-obra. 


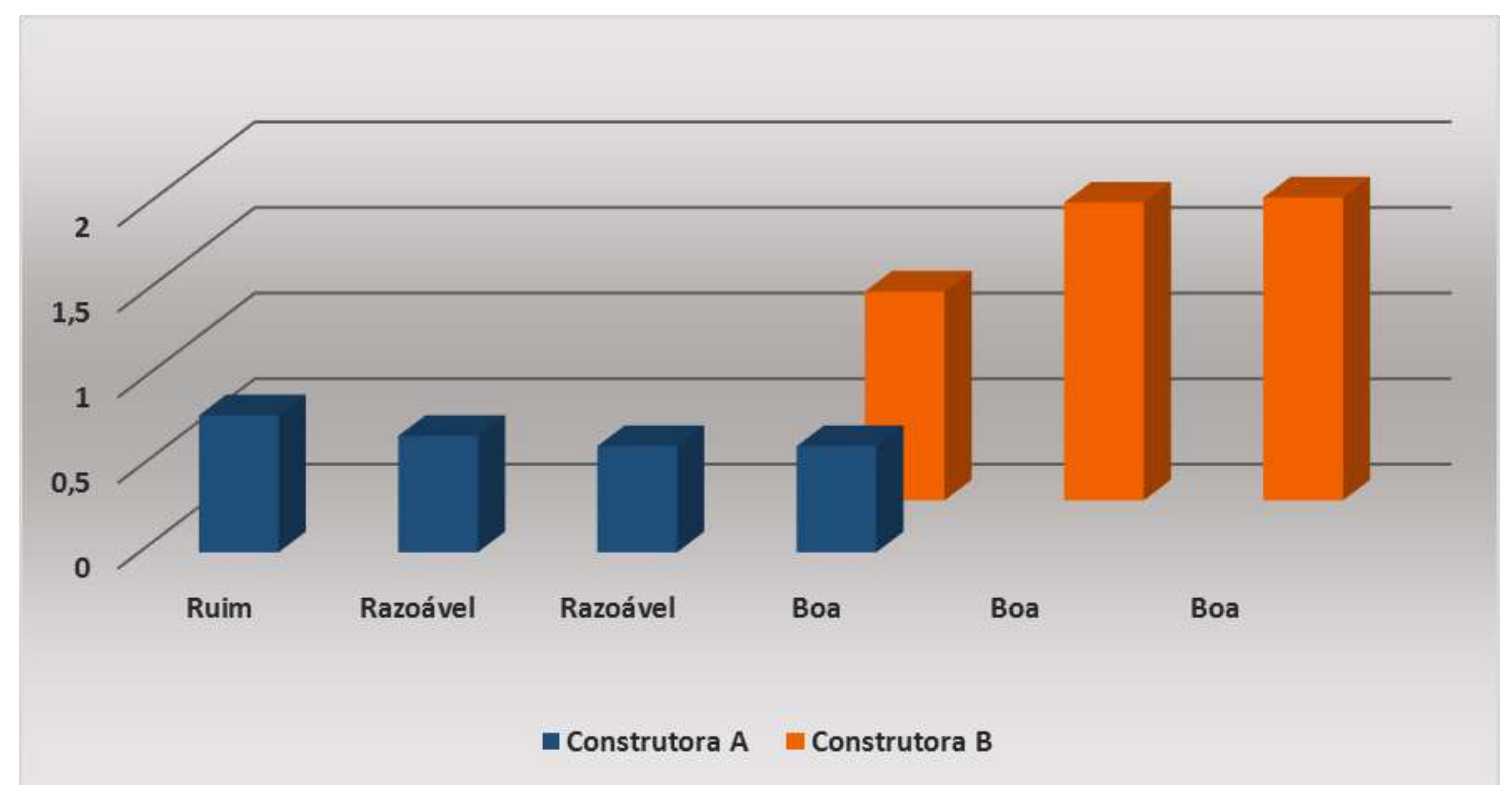

Figura 5: Geração de resíduo de acordo com a classificação da mão-de-obra

Os subempreiteiros da Construtora A foram classificados nos três níveis de mão-de-obra possíveis, com mão-de-obra boa, razoável e ruim, já a Construtora $B$, classificou todos os subempreiteiros como mão-de-obra boa.

Na Construtora A, a geração de resíduo é diretamente proporcional a qualidade da mãode-obra, o subempreiteiro classificado como mão-de-obra razoável, gera menos resíduo por área construída do que o subempreiteiro classificado como mão-de-obra ruim, e mais do que o subempreiteiro classificado como mão-de-obra boa, isso significa que, os subempreiteiros que executam o serviço com mais qualidade são os da Construtora $A$, também são os que menos geram resíduo.

Na Construtora B, observou-se resultados distintos, todos os subempreiteiros foram classificados como mão-de-obra boa, porém, houveram variações na geração de resíduos entre os subempreiteiros, isso significa que, os subempreiteiros classificados como mais qualificados da empresa, em questão de qualidade para execução do serviço, não necessariamente geram uma menor quantidade de resíduos, a classificação dada a eles não tem relação com a geração de resíduos durante o processo de assentamento cerâmico.

\subsubsection{Relação com o PBQP-H}

Um dos propósitos da pesquisa, também era realizar a verificação da relação do PBQP-H com a quantidade de resíduo gerada durante o processo, ou até mesmo se existia alguma relação. Embora não seja um dos objetivos do PBQP-H, entende-se que a geração de RCC representa um aspecto importante em termos de qualidade na construção civil, como o PBQP-H propõe melhorias em termos de qualidade para as empresas certificadas, um bom indicador seria a baixa geração de RCC.

Porém, o que se observou na pesquisa foi justamente o contrário, visto que a Construtora A não possui a certificação $P B Q P-H$, e obteve resultados melhores em relação a menor geração de resíduo durante o processo de assentamento cerâmico, do que a Construtora $B$, que possui a certificação PBQP-H. Os valores demonstram o tamanho da discrepância, a média de geração de 
resíduos por área construída da Construtora $A$ foi de $0,68 \mathrm{~kg} / \mathrm{m}^{2}$, enquanto a Construtora $B$ apresentou uma média de $1,58 \mathrm{Kg} / \mathrm{m}^{2}$.

\section{CONSIDERAÇÕES FINAIS}

O presente trabalho apresentou resultados importantes sobre o RCC, especialmente sobre a sua geração durante o processo de Assentamento Cerâmico. Obteve-se a média aritmética ponderada da geração de resíduos no processo de Assentamento Cerâmico na cidade de Criciúma, com base em sete subempreiteiros estudados de duas diferentes empresas construtoras, chegouse a uma média de 1,06 quilogramas de resíduo gerado por metro quadrado construído, salientando ainda, que esse valor representa somente uma etapa da construção.

Notou-se como duas construtoras podem apresentar resultados muito distintos, a Construtora $A$ apresentou uma média de geração de resíduo por área construída de $0,68 \mathrm{Kg} / \mathrm{m}^{2}$ durante o processo de Assentamento Cerâmico, enquanto a Construtora B apresentou uma média de $1,58 \mathrm{Kg} / \mathrm{m}^{2}$. Desta forma pode-se afirmar que para este estudo de caso a certificação em um sistema da qualidade, PBQP-H, não apresentou diminuição na geração de resíduo, pelo contrário a empresa certificada, apesar de possuir a padronização dos processos exigida pelo sistema, gerou mais resíduo.

Os resultados obtidos certamente provocam uma reflexão no que se refere a eficácia do programa, assim sugere-se replicar a pesquisa em maior número de canteiros de obras para empresas de mesmo porte para validar a afirmativa. Variáveis relacionadas ao porte das empresas, tempo de adaptação dos trabalhadores às padronizações, bem como diferenças estruturais e dos canteiros que dificultem o assentamento, apesar da uniformidade de metodologias, devem ser consideradas, já que é notável que existam fatores que podem alterar tecnicamente o volume de resíduo gerado.

Apesar de ser possível observar uma quantidade maior de resíduo da empresa que adotou o PBQP-H como filosofia de produção, estudos futuros que contemplem maiores registros se fazem necessários, uma vez que podem contribuir com inferências de natureza estatística para os dados pontualmente observados. Para trabalhos futuros, portanto, sugere-se o aproveitamento dos presentes dados, para subsidiar pesquisas que foquem tanto na redução na fonte quanto a geração de resíduos, à exemplo dos estudos sobre aplicação de Produção Mais Limpa ou outros sistemas.

\section{REFERÊNCIAS}

ABRECON. (2017) Associação Brasileira para Reciclagem de Resíduos da Construção Civil, Disponível em: <www.abrecon.org.br/> Acesso em: 25 abr. 2017

BRITSCH STANDARD INSTITUTION. (2018) BS 4887: Part 1 - Specification for air-entrainng (plasticzong) admixtures: Mortar admixtures. British Standards Institution, London, England.

Cavassin, R. T. B. (2011) Recomendações para a implementação do PBQH-H na rotina de execução de obra de edificações por meio do conhecimento tático de profissionais da área da construção civil. (Dissertação de Mestrado). Universidade Tecnológica Federal do Paraná, Departamento Acadêmico de Construção Civil, Curitiba, PR, Brasil, 81 p. 
Florim, L.C.; Quelhas, O.L.G. (2004) Contribuição para a construção sustentável: características de um projeto habitacional coeficiente. Engevista, 6(3), pp. 121-120.

Januzzi, U.A. Vercesi, C. (2010) Sistema De Gestão Da Qualidade Na Construção Civil: Um Estudo A Partir Da Experiência Do PBQP-H Junto Às Empresas Construtoras Da Cidade De Londrina. Revista Gestão Industrial, 6(3), pp. 136-160.

Junginger, M. (2003) Rejuntamento de Revestimentos Cerâmicos: Influencia das juntas de assentamento na estabilidade de painéis (Dissertação de Mestrado). Escola Politécnica da Universidade de São Paulo, Departamento de Engenharia, São Paulo, SP, Brasil, 154p.

BRASIL, Ministério das Cidades (2017) . Programa Brasileiro de Qualidade e Produtividade do Habitat. Disponível em: <http://pbqp-h.cidades.gov.br/>. Acesso em: 29 abr. 2017.

Mello, R.B. (1997) O estudo da mudança estratégica organizacional em pequenas empresas de construção: um estudo de caso em Florianópolis (Dissertação de Mestrado). Curso de Engenharia de Produção e Sistemas, Universidade Federal de Santa Catarina, Florianópolis, SC, Brasil, 194p.

Ramos, R. L.; Novaes, M. V.; Mourão, C. A. M. A. (2008) Manual de gestão ambiental de resíduos sólidos na construção civil. Cooperativa de Construção Civil do Estado do Ceará, Fortaleza, CE, Brasil, $100 \mathrm{p}$.

Paulon, V.A. Monteiro, P.J.M. (1991) Estudo da Microestrutura da Zona de Transição entre a Pasta de Cimento e o Agregado, Boletim Técnico de Escola Politécnica da USP, Departamento de Engenharia de Construção Civil, São Paulo, SP, Brasil, 182 p.

Rezende, M. A. P.; Abiko, A. K. (2004) Fatores da Inovação tecnológica nas edificações. Conferência Latino-Americana De Construção Sustentável, Anais do Encontro Nacional de Tecnologia do Ambiente Construido. São Paulo, SP, Brasil, 12 p.

Silva, M.N.P.; et al. (2015) Revestimento Cerâmicos e suas aplicabilidades. Caderno de Graduações UNIT, 2(3), pp. 87-89.

SINDUSCON (2009) Sindicato da Indústria da Construção Civil no Estado de Minas Gerais. Placas Cerâmicas para Revestimento, Programa Qualimat Sinduscon, Belo Horizonte, MG, Brasil.

TOLEDO, R. de; ABREU, A. F. de; JUNGLES, A. E. A. (2000) Difusão de inovações tecnológicas na indústria da construção civil. Anais do Encontro Nacional De Tecnologia do Ambiente Construido, Salvador, BA, Brasil, 8 p. 